KOMUNIKASI RINGKAS

\title{
PENGAWETAN KISTA ARTEMIA DAN UJI PERTUMBUHAN BIOMASSANYA
}

\author{
Bagus Sediadi Bandol Utomo*), Sri Amini") dan Thamrin Wikanta")
}

\begin{abstract}
ABSTRAK
Pengawetan kista basah Artemia salina berasal dari tambak garam rakyat Madura telah dilakukan dengan cara merendamnya dalam larutan garam 250 ppt pada suhu kamar selama satu bulan. Hasil penelitian menunjukkan bahwa daya tetas kista awetan berkurang menjadi $41,0 \%$ dibandingkan kista basah sebelum diawet yaitu $55,9 \%$. Adapun kista awetan kering mempunyai daya tetas yang jauh lebih rendah, yakni hanya $38,6 \%$ dibandingkan dengan kista tanpa diawet kering yakni $56 \%$. Sebagai pembanding, kista impor mempunyai daya tetas $59 \%$. Pengamatan pertumbuhan biomassa artemia berasal dari kista awetan dilakukan dengan pemeliharaan nauplii artemia di dalam bak-bak pemeliharaan berisi 150 liter media air laut dengan salinitas antara 55-95 ppt, $\mathrm{pH} 8,0-8,4$ dan suhu $25,6-30,5^{\circ} \mathrm{C}$. Selama budidaya nauplii artemia yang berasal dari kista basah dan kista impor dipelihara dan diberi pakan ragi roti, Tetraselmis, Spirulina dan Chaetoceros. Pemupukan media budidaya dilakukan seminggu sekali dengan pemberian urea dan TSP (1:1) sebanyak 1 ppm. Hasil penelitian menunjukkan bahwa laju pertumbuhan harian kista awetan dan kista impor tidak berbeda nyata yaitu sekitar $14 \%$. Kandungan asam lemak dan asam amino yang terdapat pada nauplii dan artemia dewasa yang berasal dari kista awetan ternyata masih cukup baik untuk mendukung pertumbuhan larva udang/ikan budidaya.
\end{abstract}

\section{ABSTRACT: Preservation of Artemia Cysts and the Growth Performance of its Biomass. By: Bagus Sediadi Bandol Utomo, Sri Amini and Thamrin Wikanta}

Preservation of wet cysts of Artemia salina originated from salt pond in Madura was done by soaking the cysts in salt water of 250 ppt salinity at room temperature for one month. The hatching percentage of the preserved cysts decreased to $41.0 \%$, compared to the unpreserved cysts, which was $55.9 \%$. After dried, the hatching percentage of preserved cysts was decreased up to $38.6 \%$ compared to the dried unpreserved one which was still $56 \%$. The hatching rate of imported cysts was $59 \%$. To observe the growth of artemia biomass, artemia nauplii which had hatched from preserved cysts was grown in tanks containing 150 sea water with the salinity ranged from 55 to $95 \mathrm{ppt}, \mathrm{pH}$ between 8,0-8,4 and the temperature between 25,6-30,5 $\mathrm{C}$. During the culture, the biomass was fed with yeast bread, Tetraselmis, Spirulina, and Chaetoceros. Fertilization of the culture media was done once a week using fertilizers of urea and TSP (1:1) with the concentration of $1 \mathrm{ppm}$. Results showed that the daily growth rate of the biomass both from preserved and imported cysts were not significantly different i.e around 14\%. Fatty acids and amino acids content in nauplii and adult artemia originated from preserved cysts were considered good enough to support feeding of shrimp and fish larvae.

KEYWORDS: preservation, Artemia salina, cysts, biomass, hatching rate, nauplii, larvae.

\section{PENDAHULUAN}

Artemia salina merupakan pakan larva udang dan ikan yang banyak digunakan di panti-panti benih udang (hatchery) di seluruh Indonesia. Artemia salina merupakan jenis krustasea tingkat rendah dari phylum Arthropoda yang banyak mengandung nutrisi seperti karbohidrat, lemak, protein dan asamasam amino. Benih ikan dan udang pada stadia awal mempunyai saluran pencernaan yang masih sederhana sehingga memerlukan nutrisi pakan jazad renik yang mengandung nilai gizi tinggi. Nauplius artemia mempunyai kandungan protein sekitar $63 \%$ dari berat keringnya.

\footnotetext{
-) Peneliti pada Pusat Riset Pengolahan Produk dan Sosial Ekonomi Kelautan dan Perikanan
} 
Artemia salina dapat hidup di perairan yang bersalinitas tinggi antara $60-300 \mathrm{ppt}$ dan mempunyai toleransi tinggi terhadap kandungan oksigen dalam air (Vos dan Rosa, 1980). Oleh karena itu potensial untuk dibudidayakan di tambak-tambak yang bersalinitas tinggi di Indonesia. Budidaya artemia mempunyai prospek yang sangat baik untuk dikembangkan dengan upaya untuk memanfaatkan baik kista maupun biomassanya menjadi produk kering yang mempunyai nilai ekonomis tinggi untuk mendukung usaha budidaya udang dan ikan. Budidaya artemia dapat dikembangkan di masyarakat sebab teknik dan peralatan yang digunakan relatif sederhana dan murah sehingga tidak menuntut ketrampilan khusus dan modal besar.

Walaupun demikian, hampir seluruh kebutuhan artemia untuk budidaya ikan masih dipenuhi dari impor. Usaha budidaya artemia secara masal di Indonesia belum banyak dikembangkan walaupun tahun 1991 sudah dilakukan penelitian budidaya yang menggunakan tambak garam di pulau Madura. Penelitian budidaya artemia di tambak penggaraman terus dilakukan pada tahun-tahun berikutnya oleh Badan Litbang Pertanian, BPPT maupun institusi riset lainnya. Pengembangan usaha budidaya kemudian dilakukan oleh Balai Budidaya Air Payau Jepara, Direktorat Jenderal Perikanan pada tahun 1995-1996 (Anonim, 1998).

Belum berkembangnya usaha budidaya artemia sangat disayangkan karena potensi sumberdaya yang sesuai untuk produksi kista artemia cukup tersedia. Meskipun teknologi budidayanya sudah dikuasai, masih perlu dilakukan penyempurnaan cara penanganan dan pengawetan kista basah khususnya yang berasal dari tambak garam rakyat agar mutunya dapat menyamai kista impor.

\section{BAHAN DAN METODA}

Bahan baku yang digunakan pada penelitian ini adalah kista basah artemia yang diambil dari tambak garam di Pamekasan, Madura.

Pengawetan kista basah dilakukan dengan dua cara, yaitu: 1) perendaman dalam larutan garam 250 ppt selama satu bulan dan 2) perendamaan dalam larutan garam $250 \mathrm{ppt}$ selama satu bulan diteruskan dengan pengeringan menggunakan rotary drum dryer. Selama perendaman, setiap 2 minggu dilakukan pencucian dan penggantian larutan garam.

Larutan garam dibuat dengan cara melarutkan garam kristal yang berasal dari tambak garam, kemudian disaring menggunakan kain katun. Kista artemia basah setelah diawetkan disimpan pada suhu kamar. Adapun pengeringan dengan rotary drum dryer (yang dirakit oleh PRPPSE) dilakukan pada suhu $35^{\circ} \mathrm{C}$, dengan kecepatan angin 1,3 m/dt selama 8 jam.

Uji penetasan kista artemia dilakukan untuk mengetahui pengaruh pengawetan kista terhadap daya tetasnya. Penetasan dengan atau tanpa dekapsulasi dilakukan di dalam wadah penetasan selama 24 dan 48 jam , dengan perbandingan 1 gram kista artemia per liter air laut. Salinitas air laut yang digunakan untuk penetasan kista adalah 30 ppt., dengan kisaran $\mathrm{pH} 7,5-8,0$ dan suhu $27-29^{\circ} \mathrm{C}$. Proses dekapsulasi kista dilakukan dengan menggunakan cara Sorgeloos et al. (1986).

Untuk mengamati kinerja nauplii yang berhasil ditetaskan, dilakukan uji pertumbuhan di dalam bak-bak pemeliharaan berukuran 150L. Media air laut yang digunakan mempunyai kisaran salinitas $50-90 \mathrm{ppt}, \mathrm{pH}$ $7,5-8,0$, suhu $28-30^{\circ} \mathrm{C}$ dan kisaran oksigen 3,0-7,0 ppm dengan padat tebar 200 ekor naupli per liter (Susanto, et al. 1993, Wardoyo, et al. 1993; Yunus, et al. 1993). Sebagai pakan digunakan pakan alami jenis Tetraselmis sp., Chaetoceros, Spirulina dan ragi roti. Pemupukan media budidaya dilakukan dengan penambahan urea : $T S P=$ $1: 1$ sebanyak 1 ppm setiap minggu.

Uji daya tetas maupun uji pertumbuhan dilakukan dengan menggunakan kista impor sebagai acuan. Pengukuran kista dan biomassa artemia dilakukan menggunakan mikrometer di mikroskop. Setelah dewasa artemia diukur menggunakan kertas milimeter.

Daya tetas kista artemia dihitung menggunakan rumus Mudjiman, (1989) sebagai berikut:

$$
H P=\frac{N}{(N+C)} \times 100 \%
$$

HP: persentase penetasan, $N$ : jumlah nauplii hasil penetasan dan $\mathrm{C}$ : jumlah kista yang tidak menetas. 
Laju pertumbuhan harian biomassa artemia dihitung menggunakan rumus sebagai berikut:

$$
a=(\text { Lt/Lo - 1) } \times 100 \%
$$

a: laju pertumbuhan, Lt: panjang pada waktu $t$, Lo: panjang pada waktu awal dan t: waktu (hari).

Kelangsungan hidup artemia dihitung dengan rumus Effendie (1979) .

\section{HASIL DAN PEMBAHASAN}

\section{Penanganan Kista}

Hasil penelitian daya tetas selama 48 jam tanpa dekapsulasi menunjukkan bahwa kista basah dari tambak garam Sampang yang belum diawetkan adalah sebesar $55,9 \%$ dengan jumlah telur sebanyak 98.100 per gram dan ukuran $215 \mu \mathrm{m}$. Setelah tetasnya berkisar $10-68 \%$, sedangkan produk dari Kanada berkisar $33-82 \%$, dan produk Kalifornia: $75-85 \%$ (Tseng, 1987).

Hasil daya tetas kista artemia yang telah diawet baik dalam keadaan basah maupun kering dengan dan tanpa dekapsulasi dapat dilihat pada Tabel 1. Terlihat bahwa daya tetas kista basah yang diawet tanpa dekapsulasi dengan lama penetasan 48 jam, mengalami penurunan dari $55,9 \%$ menjadi $26,8 \%$ dan kista kering dari $56 \%$ menjadi $14,6 \%$. Hal itu dimungkinkan karena pengaruh waktu penyimpanan pada suhu kamar masing-masing kista artemia yang sudah berumur 1 bulan mengakibatkan kemunduran daya tetasnya. Sedangkan kista impor pada kondisi penetasan yang sama mempunyai daya tetas $33,6 \%$.

Ukuran artemia pada stadia nauplius pada penetasan 24 jam dan 48 jam dengan tanpa dekapsulasi tidak jauh berbeda dari kista impor (Tabel 2).

Tabel 1. Rata-rata daya tetas kista Artemia salina (\%)

Table 1. Means of hatching percentage of Artemia salina cysts (\%)

\begin{tabular}{|c|c|c|c|c|}
\hline \multirow{2}{*}{$\begin{array}{l}\text { Jenis kista } \\
\text { Types of cysts }\end{array}$} & \multicolumn{2}{|c|}{$\begin{array}{l}\text { Tidak didekapsulasi } \\
\text { No Decapsulation }\end{array}$} & \multicolumn{2}{|c|}{$\begin{array}{l}\text { Didekapsulasi } \\
\text { Decapsulation }\end{array}$} \\
\hline & $\begin{array}{c}24 \text { jam } \\
24 \text { hours }\end{array}$ & $\begin{array}{c}48 \text { jam } \\
48 \text { hours }\end{array}$ & $\begin{array}{c}24 \text { jam } \\
24 \text { hours }\end{array}$ & $\begin{array}{l}48 \text { jam } \\
48 \text { hours }\end{array}$ \\
\hline $\begin{array}{l}\text { Kista impor } \\
\text { Imported cysts }\end{array}$ & 40,9 & 33,6 & 49,7 & 59,0 \\
\hline $\begin{array}{l}\text { Kista basah awetan } \\
\text { Wet preserved cysts }\end{array}$ & 20,0 & 26,8 & 26,0 & 41,0 \\
\hline $\begin{array}{l}\text { Kista kering } \\
\text { Dry cysts }\end{array}$ & 19,7 & 14,6 & 35,2 & 38,6 \\
\hline $\begin{array}{l}\text { Kista basah sebelum diawet } \\
\text { Wet unpreserved cysts }\end{array}$ & - & 55,9 & - & - \\
\hline $\begin{array}{l}\text { Kista kering sebelum diawet } \\
\text { Dried unpreserved cysts }\end{array}$ & - & 56,0 & - & - \\
\hline
\end{tabular}

dikeringkan, kista mempunyai daya tetas 48 jam sebesar 56\% dengan ukuran $195 \mu \mathrm{m}$ dan jumlah telur 205.800 butir per gram.

Pada percobaan yang dilakukan oleh Susanto et al. (2002), persentase penetasan kista artemia kering untuk masa penetasan 24 jam tanpa dekapsulasi adalah $21,9 \%$ atau $59,9 \%$ bila menggunakan dekapsulasi. Persentase penetasan kista artemia lokal yang dikeringkan tersebut mendekati nilai persentase penetasan kista artemia yang dilakukan oleh Yunus et al. (1994) yaitu sebesar $50,3-75,8 \%$. Adapun kista artemia impor, terutama produk dari Utah, daya

\section{Biomassa Artemia}

Pengamatan biomassa artemia yang diawetkan dilakukan dengan membudidayakannya dalam bak-bak berukuran 150 liter dengan pemberian pakan ragi roti dan plankton yang dipupuk dengan urea : TSP (1: 1) sebanyak $1 \mathrm{ppm}$ setiap minggu. Pertumbuhan panjang biomassa artemia dan kelangsungan hidup artemia awetan diamati dengan membandingkannya dengan kista impor.

Rata-rata ukuran panjang biomassa artemia awetan selama 30 hari pemeliharaan 
Tabel 2. Rata-rata ukuran nauplii artemia $(\mu \mathrm{m})$

Table 2. Means of artemia nauplii size $(\mu \mathrm{m})$

\begin{tabular}{|c|c|c|c|c|}
\hline \multirow{2}{*}{$\begin{array}{l}\text { Jenis kista } \\
\text { Types of cysts }\end{array}$} & \multicolumn{2}{|c|}{$\begin{array}{l}\text { Tidak didekapsulasi } \\
\text { No Decapsulation }\end{array}$} & \multicolumn{2}{|c|}{$\begin{array}{l}\text { Didekapsulasi } \\
\text { Decapsulation }\end{array}$} \\
\hline & $\begin{array}{c}24 \text { jam } \\
24 \text { hours }\end{array}$ & $\begin{array}{c}48 \text { jam } \\
48 \text { hours }\end{array}$ & $\begin{array}{l}24 \text { jam } \\
24 \text { hours }\end{array}$ & $\begin{array}{c}48 \text { jam } \\
48 \text { hours }\end{array}$ \\
\hline $\begin{array}{l}\text { Kista impor } \\
\text { Imported cysts } \\
\text { Kista basah awetan }\end{array}$ & 525 & 780 & 485 & 760 \\
\hline Wet preserved cysts & 545 & 675 & 495 & 780 \\
\hline $\begin{array}{l}\text { Kista kering } \\
\text { Dry cysts }\end{array}$ & 430 & 700 & 500 & 700 \\
\hline
\end{tabular}

mencapai $10.760 \mathrm{~mm}$ dan biomassa artemia impor $10.300 \mathrm{~mm}$. Adapun rata-rata sintasan biomassa artemia awetan dan artemia impor masing- masing adalah $40,0 \%$ dan $40,9 \%$ (Tabel 3)

Laju pertumbuhan harian artemia dapat dilihat pada Tabel 4 dengan nilai yang berkisar dari sekitar $5 \%$ pada hari ke 3 menjadi hampir $15 \%$ untuk kedua jenis kista. Hal ini menggambarkan bahwa kista awetan tidak berbeda dibandingkan kista impor baik dalam hal ukuran nauplii, sintasan maupun laju pertumbuhan. Pada minggu ketiga artemia mengalami ovulasi dengan perbandingan jantan dan betina rata-rata pada semua perlakuan sama yaitu 1:2 (jantan : betina).
Pengamatan kualitas media budidaya di dalam bak-bak pemeliharaan selama penelitian menunjukkan kisaran salinitas 5595 ppt, oksigen terlarut $3,0-5,9 \mathrm{ppm}, \mathrm{pH} 8,0$ 8,4 dan suhu $25,6-30,5^{\circ} \mathrm{C}$. Adapun hasil analisa nitrit rata-rata 0,0011-0,0097, sedangkan amoniak dan $\mathrm{H}_{2} \mathrm{~S}$ tidak terdeteksi.

\section{Nilai Gizi}

Hasil analisa kandungan lemak dan asam amino biomassa artemia hasil budidaya kista awetan di bak-bak pemeliharaan dapat dilihat pada Tabel 5 dan 6 . Hal tersebut menunjukkan bahwa baik nauplii maupun artemia dewasa hasil budidaya kista awetan masih memiliki kandungan asam lemak dan amino

Tabel 3. Rata-rata kelangsungan hidup Artemia salina (\%)

Table 3. Means of survival rates of Artemia salina (\%)

\begin{tabular}{lcccc}
\hline \multicolumn{1}{c}{$\begin{array}{c}\text { Jenis kista } \\
\text { Types of cysts }\end{array}$} & $\begin{array}{c}\text { Hari ke 1 } \\
\text { Day 1 }\end{array}$ & $\begin{array}{c}\text { Hari ke 5 } \\
\text { Day 5 }\end{array}$ & $\begin{array}{c}\text { Hari ke 10 } \\
\text { Day 10 }\end{array}$ & $\begin{array}{c}\text { Hari ke 30 } \\
\text { Day 30 }\end{array}$ \\
\hline $\begin{array}{l}\text { Kista basah awetan } \\
\text { Wet preserved cysts } \\
\begin{array}{l}\text { Kista impor } \\
\text { Imported cysts }\end{array}\end{array}$ & 100 & 90,5 & 83,7 & 40,0 \\
\hline
\end{tabular}

Tabel 4. Rata-rata laju pertumbuhan Artemia salina (\%)

Table 4. Average growth rates of Artemia salina (\%)

\begin{tabular}{lccccc}
\hline $\begin{array}{c}\text { Jenis kista } \\
\text { Types of cysts }\end{array}$ & $\begin{array}{c}\text { Hari ke 3 } \\
\text { Day 3 }\end{array}$ & $\begin{array}{c}\text { Hari ke 5 } \\
\text { Day 5 }\end{array}$ & $\begin{array}{c}\text { Hari ke 10 } \\
\text { Day 10 }\end{array}$ & $\begin{array}{c}\text { Hari ke 15 } \\
\text { Day 15 }\end{array}$ & $\begin{array}{c}\text { Hari ke 30 } \\
\text { Day 30 }\end{array}$ \\
\hline $\begin{array}{l}\text { Kista basah awetan } \\
\begin{array}{l}\text { Wet preserved cysts } \\
\text { Kista impor }\end{array}\end{array}$ & 5.2 & 3.6 & 6.3 & 10.1 & 14.8 \\
Imported cysts & 5.1 & 5.1 & 7.3 & 11.1 & 14.7 \\
\hline
\end{tabular}




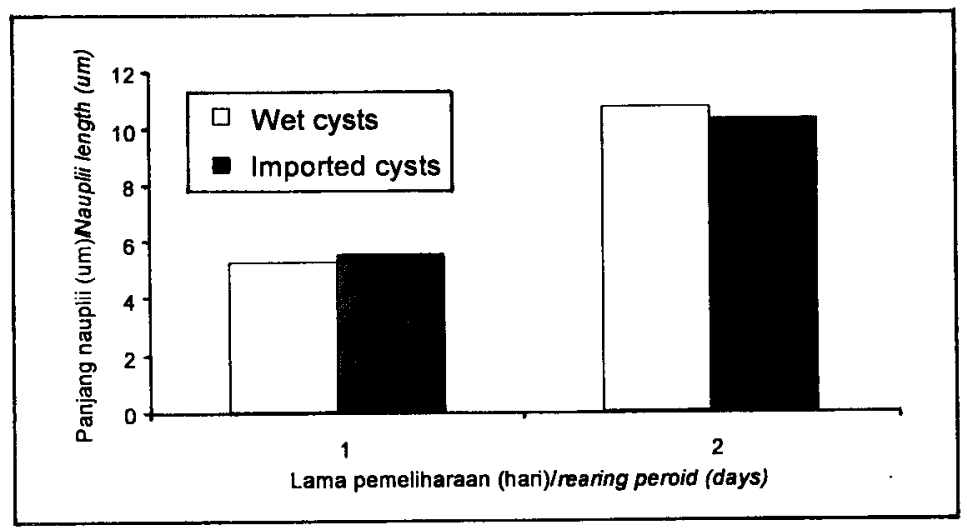

Gambar 1. Perbandingan kecepatan pertumbuhan nauplii dari kista basah dan awetan kista impor setelah 15 dan 30 hari

Figure 1. Comparation of nauplii growth rate from wet preserved cysts and imported cysts after 15 and 30 days.

Tabel 5. Jenis dan kandungan asam lemak pada Artemia salina ( $g / 100 \mathrm{~g}$ lemak)

Tabel 5. Fatty acids contents of Artemia salina ( $\mathrm{g} / 100 \mathrm{~g}$ fat)

\begin{tabular}{|c|c|c|}
\hline $\begin{array}{l}\text { Jenis asam lemak } \\
\text { Fatty acids }\end{array}$ & $\begin{array}{l}\text { Nauplii umur } 1 \text { hari } \\
\text { One day old Nauplii* }\end{array}$ & $\begin{array}{l}\text { Artemia umur } 30 \text { hari }^{\star} \\
30 \text { day old artemia* }\end{array}$ \\
\hline $\begin{array}{l}\text { C-140 miristat } \\
\text { C-160 palmitat } \\
\text { C-180 stearat } \\
\text { C-181 oleat } \\
\text { C-182 linoleat } \\
\text { C-183 linoleat } \\
\text { C-20 } 5 n-3 \text { (EPA) } \\
\text { C-22 } 6 n-3 \text { (DHA) } \\
\text { C-22 } 5 n b\end{array}$ & $\begin{array}{l}2,35 \pm 0,40 \\
1,05 \pm 0,01 \\
0,96 \pm 0,01 \\
0,48 \pm 0,02 \\
1,96 \pm 0,04 \\
2,00 \pm 0,00 \\
0,76 \pm 0,01 \\
1,49 \pm 0,00 \\
0,62 \pm 0,02\end{array}$ & $\begin{array}{l}2,39 \pm 0,33 \\
0,94 \pm 0,03 \\
0,75 \pm 0,04 \\
0,37 \pm 0,03 \\
1,85 \pm 0,09 \\
1,96 \pm 0,02 \\
0,78 \pm 0,02 \\
1,77 \pm 0,02 \\
0,54 \pm 0,01\end{array}$ \\
\hline
\end{tabular}

* Rata-rata dari dua ulangan \pm standar deviasi (Means of two replicates \pm standard deviation).

Tabel 6. Kandungan asam amino Artemia salina $(g / 100 \mathrm{~g})$

Table 6. Amino acid content of Artemia salina (g/100g)

\begin{tabular}{|c|c|c|}
\hline $\begin{array}{l}\text { Asam amino } \\
\text { Amino acid }\end{array}$ & $\begin{array}{l}\text { Nauplii umur } 1 \text { hari* } \\
\text { One day old Nauplii* }\end{array}$ & $\begin{array}{l}\text { Artemia umur } 30 \text { hari* }^{\star} \\
30 \text { day old artemia* }\end{array}$ \\
\hline $\begin{array}{l}\text { Asam aspartat/Aspartic acid } \\
\text { Asam glutamat/Glutamic acid } \\
\text { Serin/Serine } \\
\text { Glysin/Glysine } \\
\text { Histidin/Histidine } \\
\text { Arginin/Arginine } \\
\text { Treonin/Threonine } \\
\text { Alanin/Alanine } \\
\text { Prolin/Proline } \\
\text { Tirosin/Tyrosine } \\
\text { Valin/Valine } \\
\text { Metionin/Methionine } \\
\text { Isoleusin//soleucine } \\
\text { Leusin/Leucine } \\
\text { Phenilalanin/Phenylalanine } \\
\text { Lisin/Lysine }\end{array}$ & $\begin{array}{l}0,83 \pm 0,08 \\
2,09 \pm 0,05 \\
0,35 \pm 0,01 \\
0,57 \pm 0,01 \\
1,01 \pm 0,01 \\
0,77 \pm 0,02 \\
1,37 \pm 0,03 \\
0,97 \pm 0,01 \\
2,00 \pm 0,00 \\
1,95 \pm 0,01 \\
1,06 \pm 0,04 \\
1,47 \pm 0,07 \\
2,06 \pm 0,06 \\
1,23 \pm 0,02 \\
0,99 \pm 0,01 \\
4,50 \pm 0,15\end{array}$ & $\begin{array}{l}1,08 \pm 0,06 \\
3,03 \pm 0,09 \\
0,18 \pm 0,01 \\
0,48 \pm 0,02 \\
0,93 \pm 0,02 \\
1,17 \pm 0,05 \\
1,27 \pm 0,03 \\
0,95 \pm 0,01 \\
2,17 \pm 0,03 \\
1,67 \pm 0,25 \\
1,27 \pm 0,01 \\
1,35 \pm 0,05 \\
2,13 \pm 0,02 \\
1,03 \pm 0,03 \\
1,01 \pm 0,01 \\
3,84 \pm 0,13\end{array}$ \\
\hline
\end{tabular}

"Rata-rata dari dua ulangan \pm standar deviasi (Means of two replicates \pm standard deviation) 
yang cukup baik untuk mendukung pertumbuhan larva-larva udang dan ikan budidaya.

\section{KESIMPULAN}

Daya tetas kista basah sebelum diawet adalah 55,9 \% dan kista impor 59,0\%. Penyimpanan kista basah dalam larutan garam $250 \mathrm{ppt}$ selama satu bulan menyebabkan kemunduran daya tetasnya menjadi $41,0 \%$. Adapun daya tetas kista kering awetan adalah $38,6 \%$ jauh lebih rendah dibandingkan daya tetas kista kering yang tidak diawet, yakni 56\%. Ukuran nauplii artemia pada pengamatan 24 dan 48 jam pada semua jenis kista tidak menunjukkan perbedaan yang nyata.

Laju pertumbuhan biomassa artemia yang berasal dari kista awetan ataupun impor mempunyai nilai yang tidak berbeda yaitu $14 \%$ pada akhir penelitian selama 30 hari. Nilai gizi asam lemak dan asam amino nauplii maupun artemia dewasa hasil budidaya kista awetan juga masih cukup baik untuk mendukung pertumbuhan larva udang atau ikan budidaya.

\section{DAFTAR PUSTAKA}

Anonim. 1998. Laporan Awal Kegiatan Pengembangan Budidaya Artemia Terpadu Ditambak Garam Rakyat Kabupaten Daerah Tingkat II Sampang Tahun Anggaran 1998/1999. Dinas Perikanan Daerah, Sampang. 29 p.

Effendie, M.I., 1979. Metoda Biologi Perikanan. I. Yayasan Dewi Sri, Bogor.112 p.
Mudjiman, A., 1989. Udang Renik Air Asin (Artemia salina). P.T. Bharata Niaga Media, Jakarta. $149 \mathrm{p}$.

Sorgeloos, P., Lavens, P., Keger, P., Tackaert, W. and Versichele, D. 1986. Manual For The Culture And Use of Brine Shrimp Artemia in Aquaculture. Faculty of Agriculture. State University of Ghent. Belgium. $319 \mathrm{p}$.

Susanto B., Aslianti, T., Utomo, B.S.B., Basmal, J. dan Wahyuadi. K. 2002. Uji Coba Pengeringan Kista Artemia Produksi Lokal Dengan Tiga Metoda Pengeringan Yang Berbeda (in press).

Susanto B., Yunus, Achmad, T., dan Wahyuadi, K. 1993. Uji coba pemanfaatan bungkil kelapa untuk menghasilkan kista dan biomassa artemia di tambak. Jumal Penelitian Budidaya Pantai. 9(1): 9-22

Tseng, W.Y. 1987. Shrimp Mariculture A Practical Manual. The University of Papua New Guinea. Departement of Fisheries. Papua New Guinea. 133-137p.

Vos, J. and Rosa, D.L. 1980. Manual on Artemia Production in Salt Pond in The Philippines, FAO/UNDP- BFBC. Brackishwater Aquaculture Demonstration and Training Project $\mathrm{PHI} / 751005.45 \mathrm{p}$.

Wardoyo, Susanto, B., Yunus, Sugama, K., Darmansyah. 1993. Pemanfaatan beberapa pupuk organik dalam budidaya artemia salina ditambak Pejarakan, Bali. Prosiding Seminar Hasil Penelitian Perikanan Budidaya Pantai, Maros, 135-139 p.

Yunus, Ahmad, T., Wahyuadi. 1993. Pengembangan Substitusi Bungkil Kelapa Untuk Meningkatkan Mutu Kista Artemia. Laporan Hasil Penelitian Sub Balai Penelitian Perikanan Budidaya Pantai, Gondol. Hal. 21.

Yunus, Wardoyo, T. Ahmad. 1994. Kualitas nauplius hasil pemupukan berbeda dan teknik pengeringan kista artemia. Jurnal Penelitian Budidaya Pantai. 10(1): 77-83. 